\title{
The hydro-morphological index of diversity \\ A tool for describing habitat heterogeneity in river engineering projects
}

\author{
Journal Article \\ Author(s): \\ Gostner, Walter; Alp, Maria; Schleiss, Anton J.; Robinson, Christopher T. \\ Publication date: \\ 2013-07 \\ Permanent link: \\ https://doi.org/10.3929/ethz-b-000061189 \\ Rights / license: \\ In Copyright - Non-Commercial Use Permitted \\ Originally published in: \\ Hydrobiologia 712(1), https://doi.org/10.1007/s10750-012-1288-5
}




\title{
The hydro-morphological index of diversity: a tool for describing habitat heterogeneity in river engineering projects
}

\author{
Walter Gostner • Maria Alp • Anton J. Schleiss • \\ Christopher T. Robinson
}

Received: 13 January 2012/ Accepted: 19 August 2012/Published online: 11 September 2012

(C) Springer Science+Business Media B.V. 2012

\begin{abstract}
We present a new hydro-morphological index of diversity (HMID), a tool aimed for use in river engineering projects and firstly developed at gravel-bed streams in Switzerland, but intended for a broader use. We carried out field work with extensive hydraulic and geomorphic data collection, conducted correlation analysis with hydro-morphological variables, formulated the HMID, and analyzed the correlation between HMID and a visual habitat assessment method. The HMID is calculated by means of the coefficient of variation of the hydraulic variables flow velocity and water depth, which have been demonstrated to sufficiently represent the hydro-morphological heterogeneity of alpine gravel-bed stream reaches.
\end{abstract}

Guest editors: A. Elosegi, M. Mutz \& H. Piégay / Form and function: channel form, hydraulic integrity, and river ecosystem functioning

Electronic supplementary material The online version of this article (doi:10.1007/s10750-012-1288-5) contains supplementary material, which is available to authorized users.

W. Gostner $(\bowtie)$. A. J. Schleiss

Laboratory of Hydraulic Constructions (LCH),

Ecole Polytechnique Fédérale de Lausanne (EPFL),

Station 18, 1015 Lausanne, Switzerland

e-mail: w.gostner@ipp.bz.it

URL: http://lchwww.epfl.ch/

M. Alp · C. T. Robinson

Department of Aquatic Ecology, Swiss Federal Institute

of Aquatic Science and Technology EAWAG,

8600 Dübendorf, Switzerland
Based on numerical modeling, the HMID can be calculated easily for a comparison of different alternatives in river engineering projects and thus achieves predictive power for design decisions. HMID can be applied at a reach-related scale in engineering programs involving geomorphic measures that aim at the enhancement of habitat heterogeneity of a stream. However, the application of HMID has to be integrated with evaluations of the long-term streambed evolvements that are considered at a catchment scale and strongly related to the sediment regime of the stream under study.

Keywords Hydromorphological diversity · Hydraulic variables - Geomorphic metrics . Correlation analysis · Gravel-bed streams . Predictive tools

\section{Introduction}

Riverine landscapes are acknowledged hotspots of biodiversity (Allan \& Castillo, 2007) that not just fulfill a number of important ecological functions, but are also of high relevance at economic and social scales. However, extensive anthropogenic exploitation of streams for water use and waste disposal, altered land use in their watersheds, as well as modification of stream morphology using traditional engineering methods, exerts a multitude of pressures on stream ecosystems. In particular, river channelization has 
pronounced negative effects on river biota, while frequently failing to reach the initial goal of flood protection. The resulting major degradation of many streams today poses a significant threat to stream ecosystem health and stability (Malmqvist \& Rundle, 2002; Jungwirth et al., 2003; Vörösmarty et al., 2010).

Policy makers have recognized the need for both sustainable flood protection management and the recovery of lost biodiversity in streams. In the European Union, the Flood Risks Directive (FRD), on the one hand, indicates a clear paradigm shift by defining flood risk management plans with a view of giving rivers more space by considering the maintenance and restoration of floodplains (European Commission, 2007). On the other hand, the Water Framework Directive (WFD) urges member states to protect, enhance, and restore all surface water bodies, with the aim of achieving good ecological status (European Commission, 2000). A comprehensive vision of these two landmark directives implies that in today's river engineering projects, not only must flood protection measures be designed in a proper way, but also that the potential for ecological improvement should be identified and appropriate measures defined to best obtain this target.

As homogenization of physical habitat is widely assumed to be the most significant threat to river biodiversity and ecosystem functioning (Allan \& Castillo, 2007), rehabilitation of hydromorphological diversity, in combination with flood protection measures, is now one of the key topics in the field of river restoration. Hence, the impacts of habitat degradation on river biota are receiving increasing attention (Vaughan et al., 2009; Armanini et al., 2010; Dunbar et al., 2010), whereas the majority of river restoration projects are conducted under the assumption that restoring physical habitat will increase biodiversity (Miller et al., 2009). However, the knowledge for the planning of hydromorphological measures in an appropriate way to enhance the ecological potential of a stream reach still offers large room for improvement.

Therefore, adequate and easy-to-use tools are needed to design projects in a way to provide the best possible potential for ecological recovery. The hydromorphological index of diversity (HMID) offers such a tool, aiming at filling a gap in the row of already available methodologies applied at different stages of restoration projects: from assessing the initial condition of a degraded stream to planning the measures most adequate for the system and finally evaluating the success of the conducted restoration (see Fig. 1).

A vast number of methods are in use in different countries to assess the ecomorphological status of streams (Table 1). These methods are based on a variety of abiotic variables, typically characterizing both geomorphic (usually including channel, bank, and floodplain) and hydraulic properties of a reach. Frequently applying standardized multimetric indices, they allow the highly multivariate nature of riverine physical habitat to be assessed, quantified, and summarized in a simplified manner (Dunbar et al., 2010). Often, the variables are classified using practically oriented techniques such as visual assessment and overall estimation, rather than quantitative techniques (Parsons et al., 2002a). Indices based on such qualitative assessment have no predictive ability, their objective being to assess the present physical status of a stream. These assessment methods are also applied to evaluate the hydromorphological success of rehabilitation measures by comparing the physical status before and after project execution (e.g., Woolsey et al., 2007).

At the design stage of river engineering projects, the step after the assessment of the initial stream condition and where a-strictly perceived-hypothetical target is identified, a "guiding image" (Kern, 1992; Jungwirth et al., 2002), is normally formulated describing a dynamic, ecologically healthy river that could exist at a given site (Palmer et al., 2005). The guiding image should consider the range of key system variables and recognize human-induced changes to the system (Jungwirth et al., 2002) in order to define a potential for restoration that realistically can be achieved. However, a guiding image represents primarily a conceptual and therefore rather qualitative framework upon which the project outlines, and is frequently oriented by a reference condition with the focus on an achievable geomorphic form, can be defined, and rehabilitation measures put into practice (Jungwirth et al., 2003).

In lotic research, many efforts have been put into the development of predictive methods aimed at modeling freshwater biota response to modification of the hydrologic regime. Hydraulic-habitat models, e.g., PHABSIM (Bovee et al., 1998), CASIMIR (Jorde et al., 2000), or MesoHabSim (Parasiewicz, 2001), 


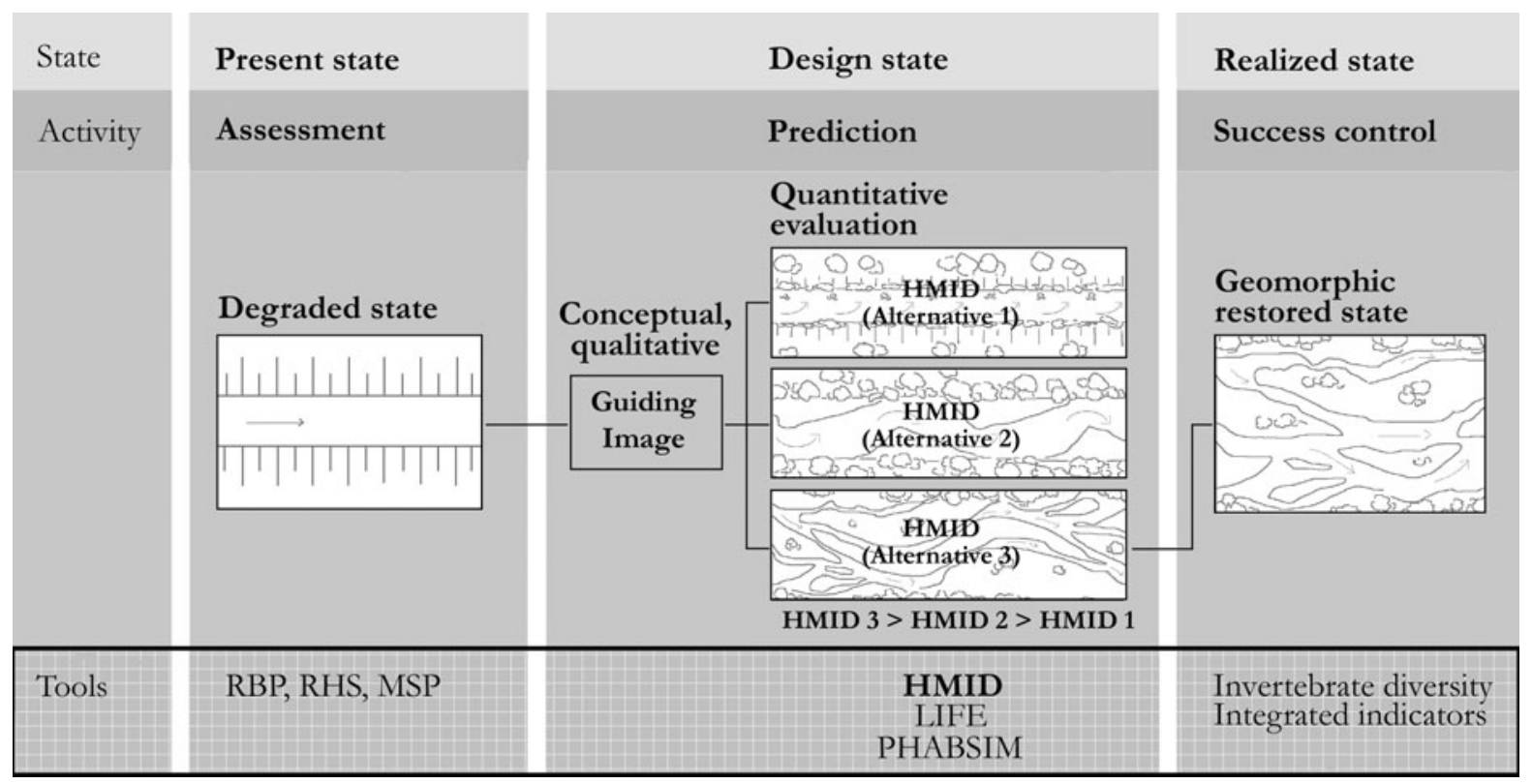

Fig. 1 Reach-related process flow diagram of thematic and temporal actions in river restoration with indication of methods and tools currently applied. Note that PHABSIM here stands for hydraulic-habitat simulation tools that are casually used also for the same purpose as HMID. River habitat survey (RHS), rapid bioassessment protocol (RBP), and modular stepwise procedure
(MSP) are shown as examples for visual habitat assessment. Lotic Invertebrate Index for Flow Evaluation (LIFE) stands for methods aiming at a comprehensive vision integrating hydrologic and morphological traits. In basic success control, invertebrate diversity is often examined; more comprehensive methods provide up to 49 indicators (Woolsey et al., 2007)

Table 1 Selection of methods for ecomorphological assessment in use in different countries

\begin{tabular}{|c|c|c|}
\hline Country & Denomination & References \\
\hline UK & River habitat survey (RHS) & Raven et al. (2000) \\
\hline Switzerland & Modular stepwise procedure (MSP) & BUWAL (1998) \\
\hline Germany & $\begin{array}{l}\text { Overview survey (large rivers) resp. On-site survey (small and } \\
\text { medium rivers) }\end{array}$ & $\begin{array}{l}\text { LAWA }(1999,2000 a, b) \text {; Fleischhacker \& Kern } \\
\text { (2002) }\end{array}$ \\
\hline Austria & Austrian habitat survey & Muhar et al. (2000) \\
\hline France & Systèmes d'évaluation de la qualité physique (SEQ) & $\begin{array}{l}\text { Agences de l'Eau \& Ministère de } \\
\text { l'Environnement (1998) }\end{array}$ \\
\hline Sweden & Riparian, Channel and Environmental Inventory & Petersen (1992) \\
\hline Italy & Index of Fluvial Functioning (IFF) & Siligardi et al. (2000) \\
\hline Australia & Australian River Assessment System (AUSRIVAS) & Parsons et al. (2002a, b) \\
\hline USA & Qualitative Habitat Evaluation Index (QHEI) & Rankin (1995) \\
\hline USA & Rapid bioassessment protocols (RBP) & Barbour et al. (1999) \\
\hline
\end{tabular}

are mostly used (Conallin et al., 2010) when anthropogenic changes in flow regime (e.g., hydropower, water abstraction) are suspected to affect biota (Gibbins \& Acornley, 2000). At the base of these methods lie species-specific preference curves in relation to single habitat-related factors such as flow velocity, water depth, substrate, or near-bed conditions
(Statzner et al., 1991; Schmedtje, 1996; Jowett, 1997; Lamouroux et al., 1998; Zappia \& Hayes, 1998; Armstrong et al., 2003; Lamouroux \& Jowett, 2005). By calculating suitability indexes for target species under different scenarios of flow management, ecologically acceptable instream flow allocations can be negotiated and prescribed. These hydraulic-habitat 
models also are applied when modifications of morphological conditions and not the change in flow regime are the key measures planned (Boavida et al., 2011). These models are rather time consuming and their predictive power is strongly dependent on the use of appropriate preference curves (Conallin et al., 2010). Some further developments, such as the LoticInvertebrate Index for Flow Evaluation LIFE (Extence et al., 1999; Dunbar et al., 2010), make an attempt to deliver an integrated vision of hydrologic and morphological modifications. However, these methods are focused primarily on the hydrology of streams and are therefore best applicable for studies of altered flow regimes (Monk et al., 2008; Buffagni et al., 2009; Armanini et al., 2010).

The intention of the presented HMID is not to replace already proven approaches and methods. As it will be demonstrated, the approach is distinguished from other methods by the following characteristics:

(i) As a predictive tool, it can be used during the design stage to evaluate and compare the effects on habitat heterogeneity of different river engineering project alternatives, whereas ecomorphological assessment methods have been developed to appraise a physically existing status;

(ii) It allows a quantitative statement concerning the improvement of the physical heterogeneity of project alternatives and can therefore be a valuable supplement for the execution of measures defined within the framework of a qualitative guiding image;

(iii) Its focus is on geomorphic measures aimed at enhancing physical diversity in contrast to hydraulic-habitat models that prevalently evaluate anthropogenic changes of the flow regime in order to allocate instream flow;

(iv) In contrast to habitat simulation models, which are often complex and time consuming, HMID, if based on numerical modeling, is straightforward and delivers clear quantitative statements, while requiring rather low effort.

Many researchers have stressed the importance of variance for ecological processes (Palmer et al., 1997). A growing body of research suggests that spatial complexity of the channel and river corridor is critical for ecosystem integrity at different scales (Thoms, 2006; Elosegi et al., 2010) and that the diversity and productivity of stream food webs are related to habitat heterogeneity (Negishi \& Richardson, 2003). The riverine ecosystem synthesis concept (RES, Thorp et al., 2006) predicts that biodiversity, system metabolism, and many other functional processes are enhanced by habitat complexity and that biocomplexity should be greater in functional process zones that are more hydrogeomorphically complex than in simpler river segments (Thorp et al., 2010).

The HMID described here was developed for river restoration projects in which increasing variance of the hydromorphological mosaic framework for spatial complexity is a key target. We conducted an extensive field campaign on three pre-alpine gravel-bed rivers in Switzerland, and analyzed correlations between hydromorphological variables. We also tested if the HMID approach and other visual ecomorphological assessment methods lead to similar results at the same study sites.

\section{Methods}

Site selection and description

We selected three Swiss pre-alpine streams for collecting data to develop the HMID (Fig. 2; Table 2). Buenz, Venoge, and Sense are gravel-bed alluvial streams characterized by a pluvial to nivo-pluvial hydrologic regime. The hydrologic regime of all study streams is mostly unaltered. The exception is a minor water withdrawal at the Venoge upstream of the V1 site. Also, a small run-of-the-river hydropower station, situated downstream of the B1 site in the Buenz, with a length of the residual reach of around $100 \mathrm{~m}$, causes occasional unnatural fluctuations of discharge due to flushing of the reservoir on an average of once per year. A high variability of morphological conditions is present along each stream, ranging from braided, nearnatural meandering or straight to partially or totally channelized as well as to partially restored reaches.

The River Buenz is a 3rd order pre-alpine river with a catchment area of $111 \mathrm{~km}^{2}$ that flows into the River Aare (Rhine drainage). It was channelized to a different extent along most of its length in the 1930s and flows mainly through agricultural areas. Several restoration projects have been conducted at the Buenz in the last two decades.

The River Venoge is a 3rd order river with a catchment area of $238 \mathrm{~km}^{2}$ and flows directly into the 


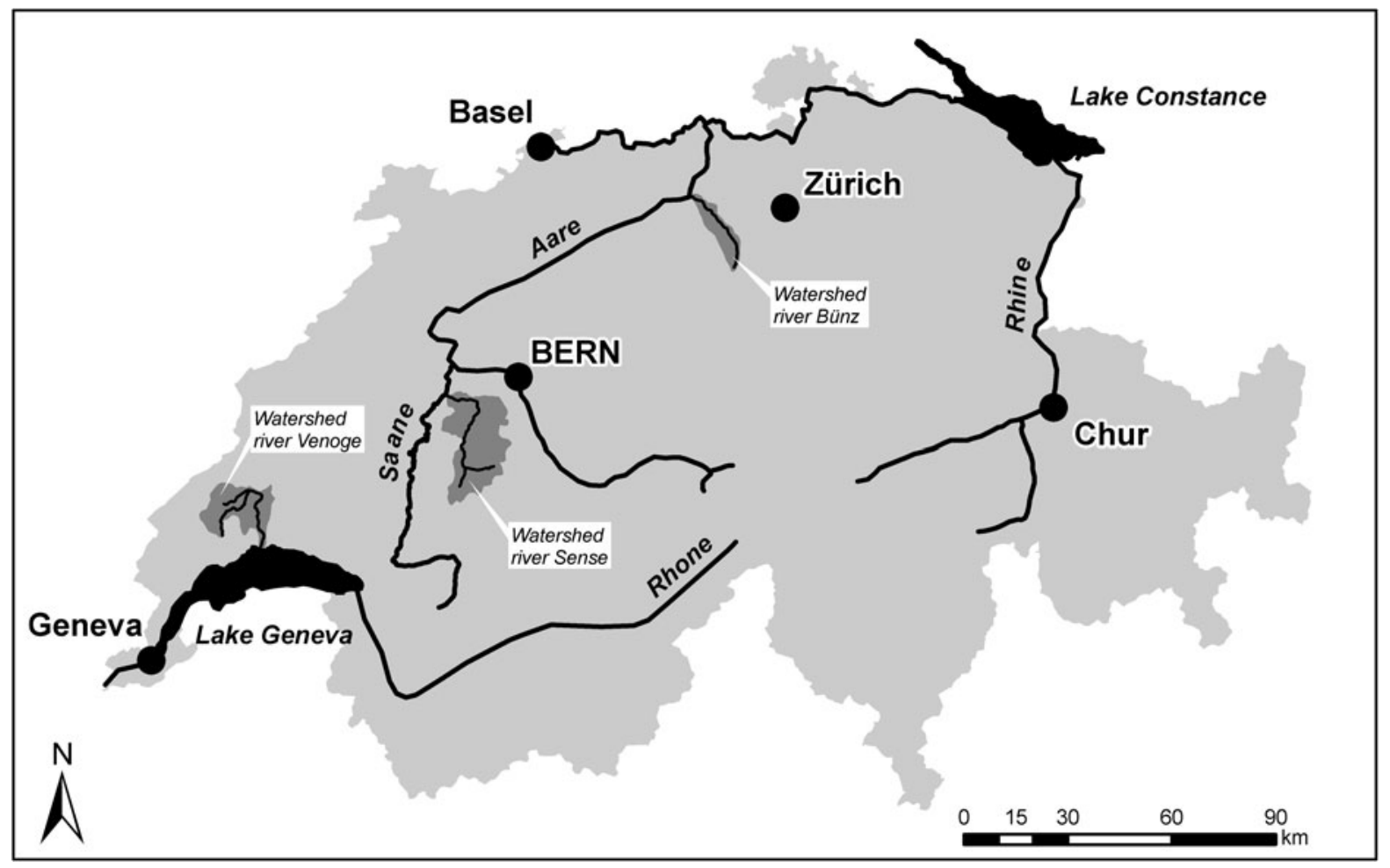

Fig. 2 Location of the study rivers in Switzerland

Lake Geneva (Rhone drainage). In its headwaters, the Venoge flows through relatively steep agricultural areas, being a naturally straight channel. Along the middle course, crossing a highly urbanized and industrialized area, it has been channelized to a high degree, whereas in its downstream part it runs as a meandering river through a flat alluvial forest.

The River Sense is a 4 th order river draining a catchment area of $432 \mathrm{~km}^{2}$ and is a tributary of the River Saane (Rhine drainage). For most of its length, the river flows through landscape intensively used for agriculture, with the exception of its headwaters which are characterized by rather untouched mountainous surroundings where forests occupy the lower areas, alpine pastures the middle belt, and high-alpine land the highest zones. For its prevailing part, the Sense is unregulated: River engineering works are almost absent along about $23 \mathrm{~km}$ of the total $35 \mathrm{~km}$ of its main stem length. Moreover, the riparian corridor provides a home to the longest alluvial forest conserved in the country. Of the investigated streams, the River Sense was thus the least affected by humaninduced stressors.
Field measurement of hydromorphological variables

We selected sites of contrasting morphology for hydromorphological measurements at each stream (Figs. 3, 4). We carried out data collection in 2008 and 2009 at predefined transects during mean flow stages. The distance between the transects was between 5 and $100 \mathrm{~m}$ depending on site morphology (Table 2). We chose the location of the transects to comprise all the hydromorphological units present at a site; thus, the total number of transects, with a minimum of 7 and a maximum of 19, varied depending on the degree of alteration of each site. Spacing between survey points along each transect was in the range between 50 and $200 \mathrm{~cm}$. By collecting a large number of data records along each transect and thus avoiding a bias effect due to a slight spacing variation between data points, we insured that the hydro-morphological stream environment could be described in a statistically representative manner. At each survey point, we measured water depth and mean flow velocity. The latter was obtained by measuring the velocity at six-tenths of depth using 
Table 2 Study site characteristics at the rivers Buenz, Venoge, and Sense

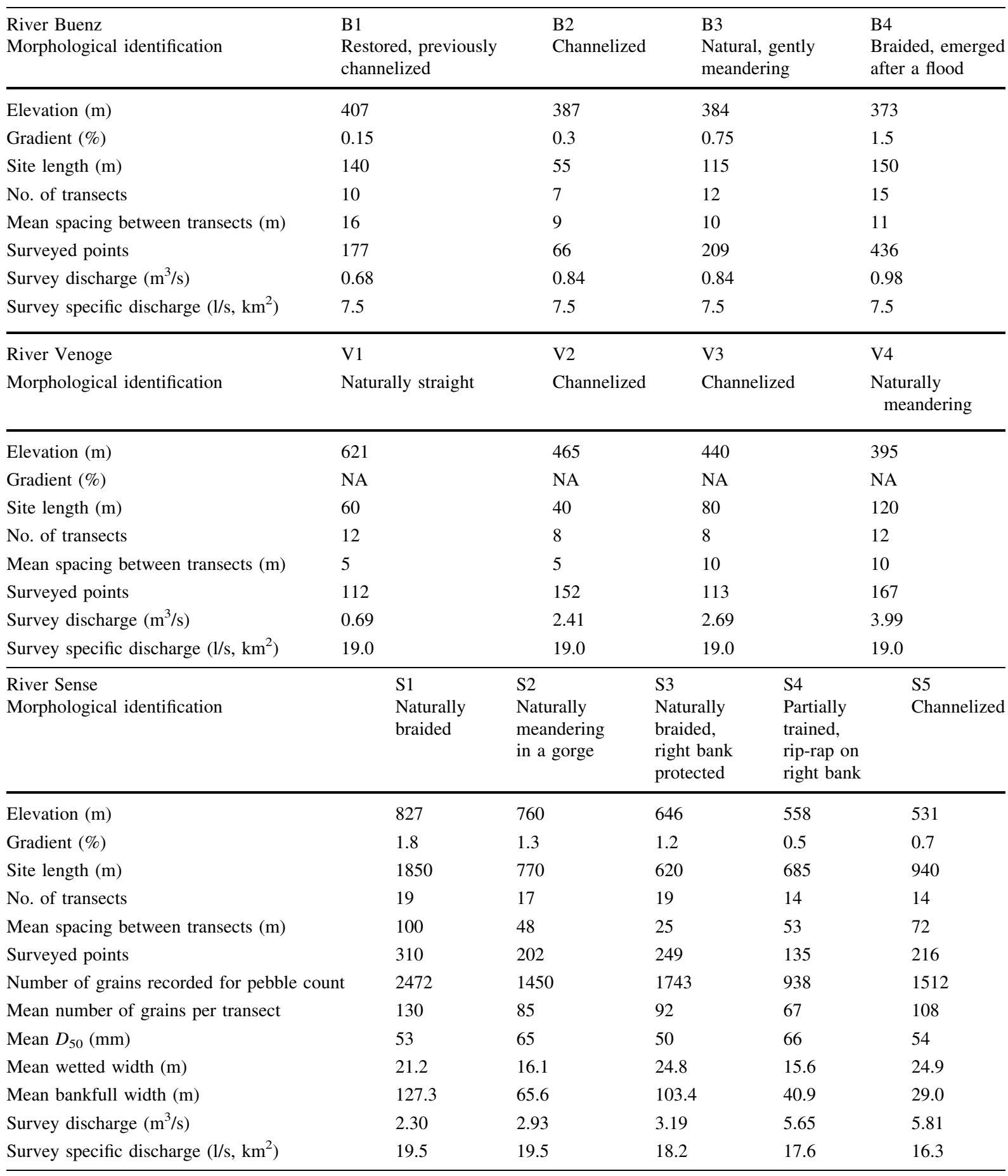

either an acoustic Doppler velocity meter (SonTek FlowTracker Handheld ADV) or an electromagnetic flow meter (Ott Nautilus Flow Sensor C2000).
Moreover, further data collection was conducted at the Sense. Bed substrate sampling along each transect was carried out according to the pebble count method 
Fig. 3 Location and morphology of study sites
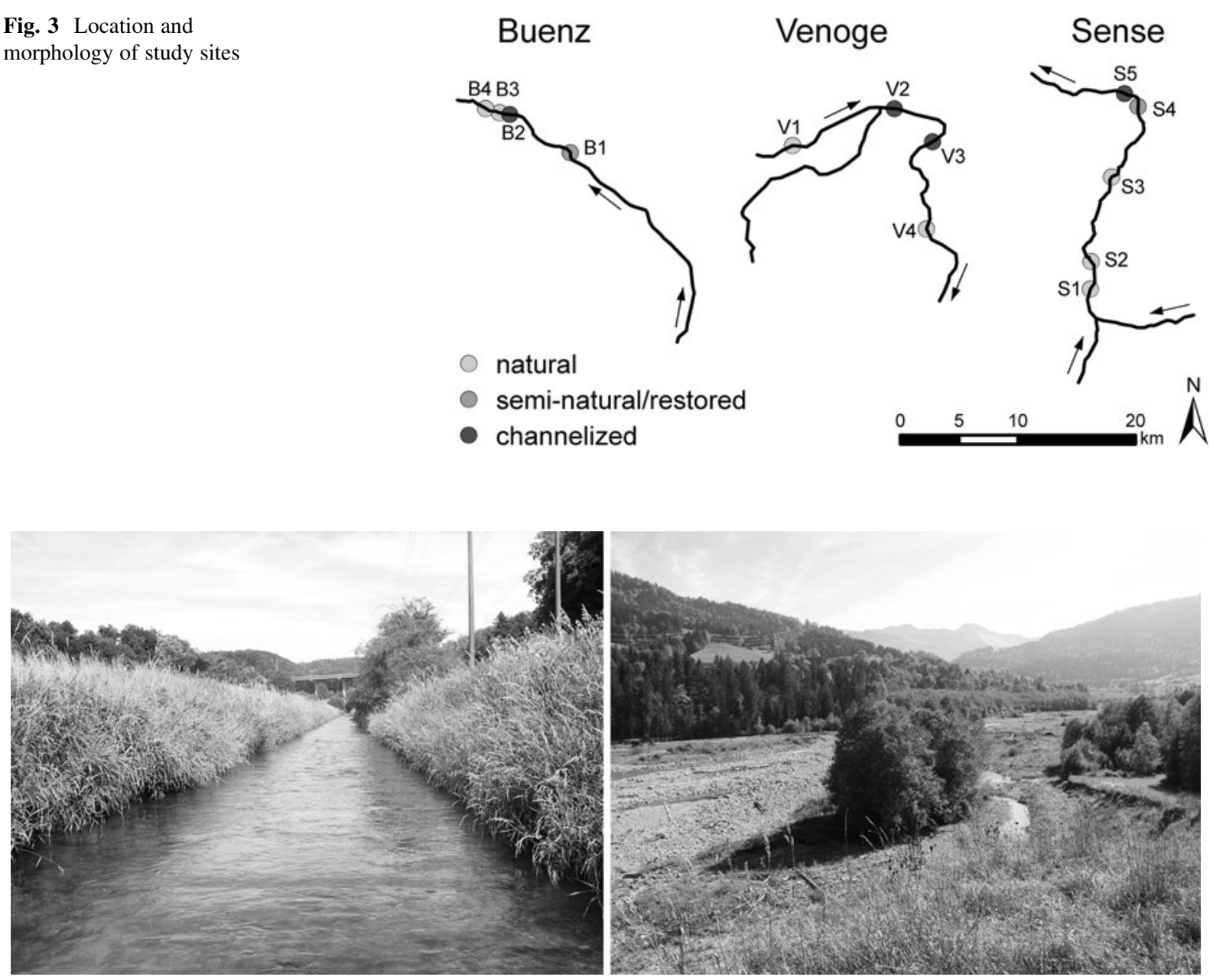

Fig. 4 Examples of the study sites. Left Channelized study site at the river Buenz (B2). Right Braided and morphologically pristine study site at the river Sense (S1)

(Wolman, 1954). It was conducted along both the wetted and non-wetted parts of each transect using the heel-to-toe walk (Bunte \& Abt, 2001) with footstep distances at around $70-120 \mathrm{~cm}$. The randomness of particle selection was maintained by picking up the particles from beneath the tip of the boot, while looking away. The total number of recorded substrate grains was in the range of 940-2,470 per site with a mean number of grains along each transect varying between 67 and 130 (Table 2). Along each transect of the river Sense, we conducted a detailed topographic survey over the whole river bed comprising the banks, using either a theodolite or a first order GPS station that allowed determination of river bed elevation, wetted width, and width at bankfull depth. The topographic survey was completed by recording the thalweg profile. The time needed to collect the data for a single site varied, for a team of 4 persons, between 1.5 and 2.5 days, depending on the complexity of the site.

For each survey point at the Sense, we calculated Reynolds and Froude numbers that have been used in other studies as descriptors in preference curves for fishes (Heede \& Rinne, 1991; Bisson et al., 1998; Bates, 2000) as well as bottom shear stress (see Appendix-electronic supplementary material for the formulae) which represents nearbed conditions considered a key hydraulic factor for river benthos (Minshall, 1984; Statzner et al., 1988). 
Preliminary work: correlation analysis

of hydromorphological data for selecting variables for HMID

\section{Selected point-related and reach-related metrics}

Physical descriptors of the abiotic environment in riverine landscapes are highly interdependent and characterized by complex and not yet fully understood cross-correlations and confounding effects at different spatial scales (Graham, 2003). However, it is known that channel form and flow are inseparably associated (Elosegi et al., 2010) and that a combination of these two factors produces the physical habitat for instream biota (Maddock, 1999). Based on data from the river Sense, we conducted statistical analyses with R 2.11.1 ( $\mathrm{R}$ Development Core Team, 2010) to test for correlations between hydraulic and geomorphic variables and reduce their number to a minimum sufficient to describe the reach condition in terms of hydromorphology. The HMID was then formulated by combining the identified key variables that best describe the hydromorphological condition of a given site.

For the correlation analysis, various metrics were considered at two different levels. The first one, henceforth denoted as point-related, concerned correlation analysis of variables measured or calculated for single survey points. This approach was applied to the hydraulic variables flow velocity, water depth, shear stress, and Froude and Reynolds number. The second level, referred to as reach-related, was applied for hydraulic and geomorphic variables that express overall diversity at a reach scale (for calculated values, see table in Appendix-electronic supplementary material). For describing the reach-related spatial diversity of flow velocity, water depth, and substrate characteristics, we used the coefficient of variation $(\mathrm{CV}=$ standard deviation $\sigma /$ mean $\mu) . \mathrm{CV}$ adjusts the sample variance by the mean and thus is a better comparative measure of variability than variance alone (Schneider, 1994). The statistical parameters $\mu, \sigma$, and $\mathrm{CV}$ of flow velocity, water depth, and grain size distribution were calculated from a single dataset per site and per variable, whereby the data recorded along the transects were pooled.

The reach-related spatial diversity of geomorphic conditions was determined on the longitudinal axis by analyzing the thalweg profile (thalweg diversity, TWD) and on the transversal axis along the transects (cross-section diversity, CSD). We expected that in a more natural reach, slopes along the thalweg profile will vary strongly due to the presence of riffle-pool sequences and thus result in higher TWD, whereas in a channelized reach, the slope along the thalweg profile is relatively uniform. TWD was determined by calculating for each survey point the height difference between the real point height and the theoretic height calculated as if the slope from the thalweg differential immediately upstream remained equal (see McCormick, 1994; Beck, 1998). Then, the absolute values of the single height differences were summed and normalized through division by the total length of the thalweg profile (see Appendix-electronic supplementary material for formulae). CSD of each study site was calculated similarly to TWD. The height differences between the recorded points along the transects were summed up and normalized by dividing this sum by the total length of the considered part of the transect. CSD was calculated related to the active streambed, omitting the banks as they, in some cases, were strongly artificial and therefore the calculation would have been distorted.

An additional geomorphic measure was introduced by calculating the mean ratio between the wetted width at mean flow and bankfull flow. At discharges below bankfull, in unregulated gravel-bed streams, the parafluvial zone of the streambed is usually wetted only partially as this area is also occupied by gravel bars with varying heights. The parafluvial zone is almost entirely wetted only at discharges close to bankfull, except for the islands with standing trees that are flooded on average every 20-30 years (Gurnell et al., 2001; Gostner et al., 2010). In contrast, at channelized streams, the wetted width only differs slightly at mean flow and bankfull flow. Therefore, we also hypothesized that the ratio between wetted width at mean flow and bankfull flow could be representative of the hydro-morphological variability of a stream reach.

\section{Correlations of selected hydraulic and geomorphic metrics}

In point-related analysis, the correlation between flow velocity and water depth was found to be weak. High velocities, in fact, could be found at both low water depth (e.g., in riffles) and in medium to high water depth areas (e.g., runs). Low flow velocities, on the 
Table 3 Correlation matrix of point-related metrics

\begin{tabular}{llllll}
\hline & $d$ & $v$ & $\tau$ & $F r$ & $R e$ \\
\hline Water depth $(d)$ & 1.00 & & & & \\
Flow velocity $(v)$ & $\mathbf{0 . 4 5}$ & 1.00 & & & \\
Shear stress $(\tau)$ & $\mathbf{0 . 1 4}$ & $\mathbf{0 . 8 4}$ & 1.00 & & \\
Froude number $(F r)$ & $\mathbf{0 . 1 3}$ & $\mathbf{0 . 8 9}$ & $\mathbf{0 . 9 2}$ & 1.00 & \\
Reynolds number $(R e)$ & $\mathbf{0 . 7 4}$ & $\mathbf{0 . 8 4}$ & $\mathbf{0 . 5 6}$ & $\mathbf{0 . 5 4}$ & 1.00
\end{tabular}

Indicates $r$-values from Pearson product momentum correlation with significant results $(P<0.05, n=1102)$ in bold

other hand, were generally present not only in areas with high water depth (e.g., pools), but also in shallow backwater zones. Complex hydraulic variables such as shear stress, Froude number, and Reynolds number incorporate flow velocity and water depth and are therefore sufficiently represented by the latter two (as was confirmed by point-related correlation analysis, Table 3).

Reach-related analysis revealed strong correlation between diversity of bed sediment and flow velocity (Table 4): The substrate mosaic was much more heterogeneous at natural sites than at channelized sites. Thus, there we found fine sediments in areas with a relatively low flow, e.g., in the wake zone of vegetation, large woody debris, or boulder clusters, or at different locations in pools. In contrast, cobbles of large diameter were associated with riffle zones. At channelized sites, diversity of flow velocity was low, heterogeneity of sediments was reduced, and clay and silt were absent. Furthermore, a strong correlation was found between hydraulic diversity and geomorphic diversity expressed as CSD or TWD (Table 4). CV of flow velocity showed a strong and significant correlation to each of the applied geomorphic metrics. Water depth diversity behaved similarly, although showing somewhat weaker correlations with the other variables than flow velocity. Moreover, the correlation within geomorphic measures was also high.

Finally, streams with a high geomorphic and hydraulic diversity were characterized by a low ratio between wetted width during mean flow stage and wetted width at bankfull flow-an indication of the importance of active parafluvial zones. This metric was also significantly correlated with the diversity of flow velocity (Table 4).

Consequently, based on correlation analysis, the heterogeneity of flow velocity and water depth was
Table 4 Correlation matrix of reach-related metrics

\begin{tabular}{|c|c|c|c|c|c|c|}
\hline & $\mathrm{CVv}$ & $\mathrm{CVd}$ & CVs & CSD & TWD & $\begin{array}{l}\mathrm{Bw} / \\
\mathrm{Bbf}\end{array}$ \\
\hline $\begin{array}{l}\text { CV flow } \\
\text { velocity } \\
(\mathrm{CVv})\end{array}$ & 1.00 & & & & & \\
\hline $\begin{array}{l}\text { CV water } \\
\text { depth } \\
(\mathrm{CVd})\end{array}$ & 0.91 & 1.00 & & & & \\
\hline $\begin{array}{l}\text { CV } \\
\text { substrate } \\
(\mathrm{CVs})\end{array}$ & 0.96 & 0.98 & 1.00 & & & \\
\hline $\begin{array}{l}\text { Cross- } \\
\text { section } \\
\text { diversity } \\
\text { (CSD) }\end{array}$ & 0.94 & 0.82 & 0.90 & 1.00 & & \\
\hline $\begin{array}{l}\text { Thalweg } \\
\text { diversity } \\
\text { (TWD) }\end{array}$ & 0.93 & 0.76 & 0.87 & 0.98 & 1.00 & \\
\hline $\begin{array}{c}\mu\left(B_{\text {wetted }} /\right. \\
\left.B_{\text {bankfull }}\right) \\
(\mathrm{Bw} / \mathrm{Bbf})\end{array}$ & -0.92 & -0.76 & -0.87 & -0.98 & -0.99 & 1.00 \\
\hline
\end{tabular}

Indicates $r$-values from Pearson product momentum correlation with significant results $(P<0.05, n=5)$ in bold. Note that CSD is the cross-section diversity related to that part of the transect belonging to the active river bed, including gravel bars, islands, secondary channels without flowing water, but excluding river banks

identified to be sufficient for detecting the overall degree of hydromorphological heterogeneity in a given stream reach.

Formulation of HMID

We based the HMID on the coefficient of variation CV of flow velocity and water depth. Partial diversity $V(i)$ of each variable was expressed as:

$V(i)=\left(1+C V_{i}\right)=\left(1+\frac{\sigma_{i}}{\mu_{i}}\right)$

The HMID of a site was formulated by multiplying the partial diversity of the hydraulic variables flow velocity $(v)$ and water depth $(d)$ as

$$
\begin{aligned}
\operatorname{HMID}_{\text {Site }} & =\prod_{i} V(i)^{2}=V(v)^{2} \cdot V(d)^{2} \\
& =\left(1+\frac{\sigma_{v}}{\mu_{v}}\right)^{2} \cdot\left(1+\frac{\sigma_{d}}{\mu_{d}}\right)^{2}
\end{aligned}
$$

Using squared values of partial diversity and multiplication of squared values of partial diversity instead of building the sum (Schleiss, 2005) spreads out the range 
of the HMID values and thus makes the index more sensitive to smaller differences in hydromorphology.

Comparison of HMID with a habitat assessment method

We compared HMID to rapid bioassessment protocols (RBP; Plafkin et al., 1989; Barbour et al., 1999). RBP is a visually based habitat assessment that evaluates the structure of the physical river habitat (Barbour et al., 1999). It includes 10 variables that characterize stream habitat at the micro- and mesohabitat scale (embeddedness, epifaunal substrate cover, velocity and depth regime, sediment deposition, frequency of riffles) as well as at the reach scale (channel flow status, channel alteration). Further factors, such as riparian and bank structure, that influence these microand macroscale features are also assessed (Barbour \& Stribling, 1991; Barbour et al., 1999). At each site, individual parameters are rated according to a continuum of scores that represent optimal, sub-optimal, marginal, or poor conditions, and that range between a 1 and 20. A total score out of a maximum score of 200 is obtained for each site and is used to assess the quality of instream and riparian habitat at a stream reach (Parsons et al., 2002b).

\section{Results}

Hydraulic variability

The range of flow velocities and water depths was narrow in channelized sites (B2, V2, C3, S5). Mean flow velocity in these sites was remarkably higher than in more natural sites with runs being the prevalent habitat (Fig. 5). The range of flow velocities and water depths was widest at sites with natural morphology (B3, B4, V1, V4, S1, S2, and S3), where a large variety of habitats from riffles, runs, and glides to pools as well as backwater areas were present.

Hydraulic variability was generally lower in channelized sites (B2, V2, V3, and S5) than in less modified ones (Table 5). In fact, within each stream, the coefficient of variation $\mathrm{CV}$ was always lowest in channelized sites. In restored sites (B1) or in partially channelized sites (S4), CV was somewhat higher, whereas the highest $\mathrm{CV}$ was found in the most natural sites (B3, B4, V1, V4, S1, S2, and S3). To summarize, we found $\mathrm{CV}$ values for water depth to be in the range of 0.2-0.5 for channelized sites and in the range of 0.6-0.7 for natural sites, whereas CV for flow velocity was usually higher, ranging between 0.2 and 0.6 for channelized and 0.7-1.1 for natural sites. The difference of $\mathrm{CV}$ between flow velocity and water depth was the highest at less modified sites, with a maximum ratio of almost 2 at the most natural sites. However, at channelized sites, CV of water depth occasionally was higher than $\mathrm{CV}$ of flow velocity.

\section{HMID value range}

The observed variability patterns were reflected in HMID values. In all streams, the channelized sites (B2, V2, V3, and S5) showed the lowest HMID (Table 5). Partially trained or restored sites (e.g., S4 and B1) had a higher HMID than respective channelized sites. Highest values for HMID were obtained for river sites with a natural physical environment, as found at B3, B4, V1, V3, S1, S2, and S3.

Overall, HMID values spanned a range of values from 2 to 12 in the studied reaches, higher HMID values corresponding to higher hydromorphological heterogeneity. Overall, the following categories, generally valid for gravel-bed rivers, could be defined according to ranges in HMID values:

(1) Low (HMID < 5) — channelized and morphologically heavily altered sites with uniform cross-sections and longitudinal slope. The theoretic lowest HMID value of 1 would be obtained by a completely regular channel without any variability in the hydraulic variables $(\sigma=0)$, whereas an HMID close to 5 corresponds to a channelized river with minor geomorphic patches as, for example, a thalweg line continuously shifting between the two bank toes.

(2) Medium $(5<$ HMID $<9)$ - stream sites at the lower end of this range were less severely modified than those of the previous category, but still showing a limited variability of hydraulic units (V4, B1). In these sites, the variability of hydraulic units was present to a certain extent, but hydromorphological patches typical to an intact natural state were not developed yet. At the upper end of this range, we found sites that in hydromorphological terms were approaching sites with natural morphology (V1, S3). 

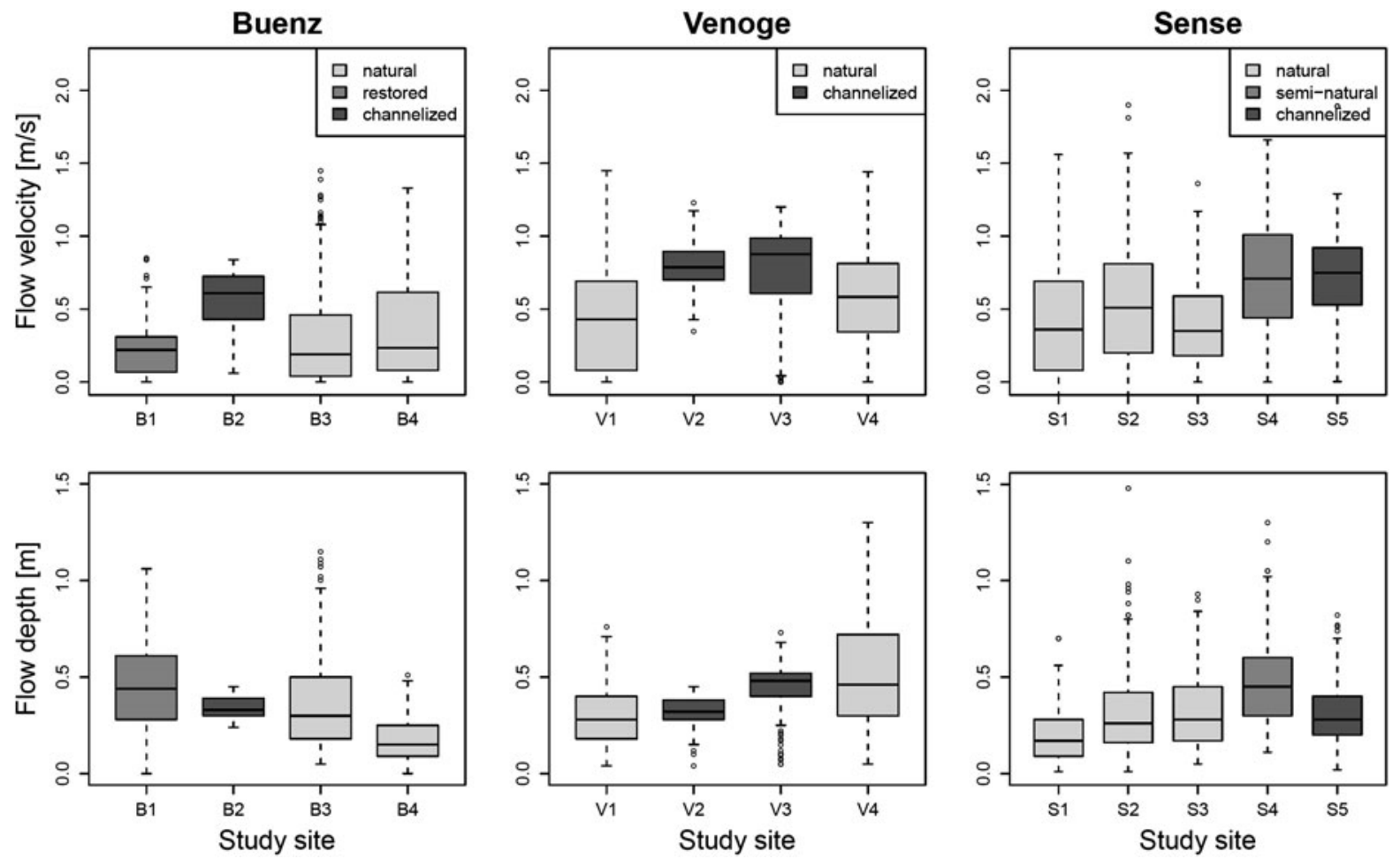

Fig. 5 Boxplots of flow velocity and water depth for the investigated sites at the rivers Buenz, Venoge, and Sense

(3) High (HMID > 9)—morphologically pristine sites where gravel-bed streams fully develop their spatial dynamics, showing the complete range of hydraulic habitats (B3, B4, S1, and S2). For river engineering projects, these sites could be classified as reference sites. We suggest that HMID values in this range should be taken as a guiding measure for geomorphic restyling of prealpine gravel-bed rivers.

\section{Correlation with RBP}

We found a strong correlation between the HMID and RBP in each of the study rivers $\left(R^{2}=0.91-0.98\right.$; Fig. 6a). Analysis of pooled normalized values for all three rivers also showed a high correlation between the two indices $\left(R^{2}=0.86, P=5.6 \times 10^{-6}\right.$; Fig. $\left.6 \mathrm{~b}\right)$.

\section{Discussion}

While identifying a gap in the range of existing planning tools for river restoration projects, we offer a solution presenting a hydro-morphological index that could fill it. We described the steps of development of the HMID and the conducted analyses to test its performance and validity. The intent of this development project was to provide the practitioner with a simple-to-use and straightforward tool to be applied in river engineering projects.

Hydraulic variables: representative descriptors of stream condition

Correlation analyses of data, recorded in preliminary field surveys assessing a range of geomorphic and hydraulic variables at both the point- and reach-level, lead us to the conclusion that most of these variables are strongly correlated. The diversity of all variables decreased with the level of reach channelization and, interestingly, the direction (longitudinal or transversal) in which geomorphic diversity was considered did not play an important role. Altogether, we conclude that at the considered spatial scale, most geomorphic and hydraulic variables are highly correlated and the hydro-morphological variability of a stream reach can 
Table 5 Mean value $(\mu)$, standard deviation $(\sigma)$, coefficient of variation $(\mathrm{CV})$, and partial diversity $(V)$ of flow velocity $(v)$ and water depth $(d)$ as well as HMID values at the study sites

\begin{tabular}{|c|c|c|c|c|c|}
\hline River Buenz & B1 & & B2 & B3 & B4 \\
\hline \multicolumn{6}{|l|}{$v(\mathrm{~m} / \mathrm{s})$} \\
\hline$\mu$ & 0.20 & & 0.56 & 0.32 & 0.37 \\
\hline$\sigma$ & 0.15 & & 0.21 & 0.35 & 0.34 \\
\hline $\mathrm{CV}$ & 0.75 & & 0.38 & 1.09 & 0.92 \\
\hline$V(v)$ & 1.75 & & 1.38 & 2.09 & 1.92 \\
\hline \multicolumn{6}{|l|}{$d(\mathrm{~m})$} \\
\hline$\mu$ & 0.46 & & 0.34 & 0.38 & 0.18 \\
\hline$\sigma$ & 0.22 & & 0.06 & 0.26 & 0.11 \\
\hline $\mathrm{CV}$ & 0.48 & & 0.18 & 0.68 & 0.61 \\
\hline$V(d)$ & 1.48 & & 1.18 & 1.68 & 1.61 \\
\hline HMID & 6.69 & & 2.62 & 12.43 & 9.56 \\
\hline River Venoge & V1 & & $\mathbf{V} 2$ & V3 & V4 \\
\hline \multicolumn{6}{|l|}{$v(\mathrm{~m} / \mathrm{s})$} \\
\hline$\mu$ & 0.45 & & 0.79 & 0.77 & 0.57 \\
\hline$\sigma$ & 0.38 & & 0.16 & 0.31 & 0.34 \\
\hline $\mathrm{CV}$ & 0.84 & & 0.20 & 0.40 & 0.60 \\
\hline$V(v)$ & 1.84 & & 1.20 & 1.40 & 1.60 \\
\hline \multicolumn{6}{|l|}{$d(\mathrm{~m})$} \\
\hline$\mu$ & 0.30 & & 0.32 & 0.44 & 0.49 \\
\hline$\sigma$ & 0.16 & & 0.08 & 0.14 & 0.26 \\
\hline $\mathrm{CV}$ & 0.53 & & 0.25 & 0.32 & 0.53 \\
\hline$V(d)$ & 1.53 & & 1.25 & 1.32 & 1.53 \\
\hline HMID & 8.00 & & 2.26 & 3.42 & 5.97 \\
\hline River Sense & S1 & S2 & S3 & S4 & S5 \\
\hline \multicolumn{6}{|l|}{$V(\mathrm{~m} / \mathrm{s})$} \\
\hline$\mu$ & 0.44 & 0.56 & 0.39 & 0.72 & 0.71 \\
\hline$\sigma$ & 0.41 & 0.45 & 0.27 & 0.42 & 0.29 \\
\hline $\mathrm{CV}$ & 0.93 & 0.80 & 0.69 & 0.58 & 0.41 \\
\hline$V(v)$ & 1.93 & 1.80 & 1.69 & 1.58 & 1.41 \\
\hline \multicolumn{6}{|l|}{$d(\mathrm{~m})$} \\
\hline$\mu$ & 0.20 & 0.32 & 0.31 & 0.46 & 0.31 \\
\hline$\sigma$ & 0.13 & 0.22 & 0.18 & 0.22 & 0.15 \\
\hline $\mathrm{CV}$ & 0.65 & 0.69 & 0.58 & 0.48 & 0.48 \\
\hline$V(d)$ & 1.65 & 1.69 & 1.58 & 1.48 & 1.48 \\
\hline HMID & 10.16 & 9.26 & 7.16 & 5.48 & 4.37 \\
\hline
\end{tabular}

be reliably quantified using a strongly reduced number of variables.

Elsewhere, it has already been argued, in fact, that morphology accurately reflects the range of flows that move through the channel (Emery et al., 2003) and can be used as a surrogate of the flow condition in a stream (Bartley \& Rutherford, 2005). In other studies, hydraulic variables were defined as a result of the interplay between flow and morphology (Maddock, 1999) and were thus stated to characterize the hydromorphological template of a stream at an ecologically relevant scale (Wallis et al., 2010). In concordance with the latter, we think that focusing directly on hydraulic variables in lieu of studying morphological characteristics of a stream is a valid approach as hydraulic variables reflect not only the hydrologic framework of a stream, but also its geomorphic template. Furthermore, complex hydraulic variables are closely correlated with basic variables such as flow velocity and water depth. Therefore, we prefer to base the description of the hydromorphological template on the latter as they are easier to measure, calculate, and interpret.

The HMID approach: using variance to describe diversity

The proposed HMID uses the coefficient of variation $\mathrm{CV}$ as a measure of diversity of hydraulic variables. $\mathrm{CV}$ is a useful measure in statistics (Rossi et al., 1992) and was found earlier to be an appropriate metric for investigation of hydromorphological diversity. The patterns found by Jähnig et al. (2008) showed that CV was generally higher at multiple-channel than at single-channel reaches, and $\mathrm{CV}$ for flow velocity was higher than $\mathrm{CV}$ for water depth, being in a similar range to the results of our study (Table 5). Other studies (Simonson et al., 1994; Negishi \& Richardson, 2003) also used the CV to evaluate diversity of hydraulic variables, for example, stating that $\mathrm{CV}$ of flow velocity was twice as high as for other variables (see Simonson et al., 1994).

Our results supported these findings. The range of values found for $\mathrm{CV}$ of flow velocity and depth was similar to those reported by Jähnig et al. (2008). We also found a higher CV of flow velocity at natural sites, whereas at more modified sites, the difference of $\mathrm{CV}$ for flow velocity and water depth mostly became smaller. Overall, our study confirmed the sensitivity of $\mathrm{CV}$ of hydraulic variables to hydromorphological diversity patterns and we felt confident to develop the HMID based on this statistical metric. 

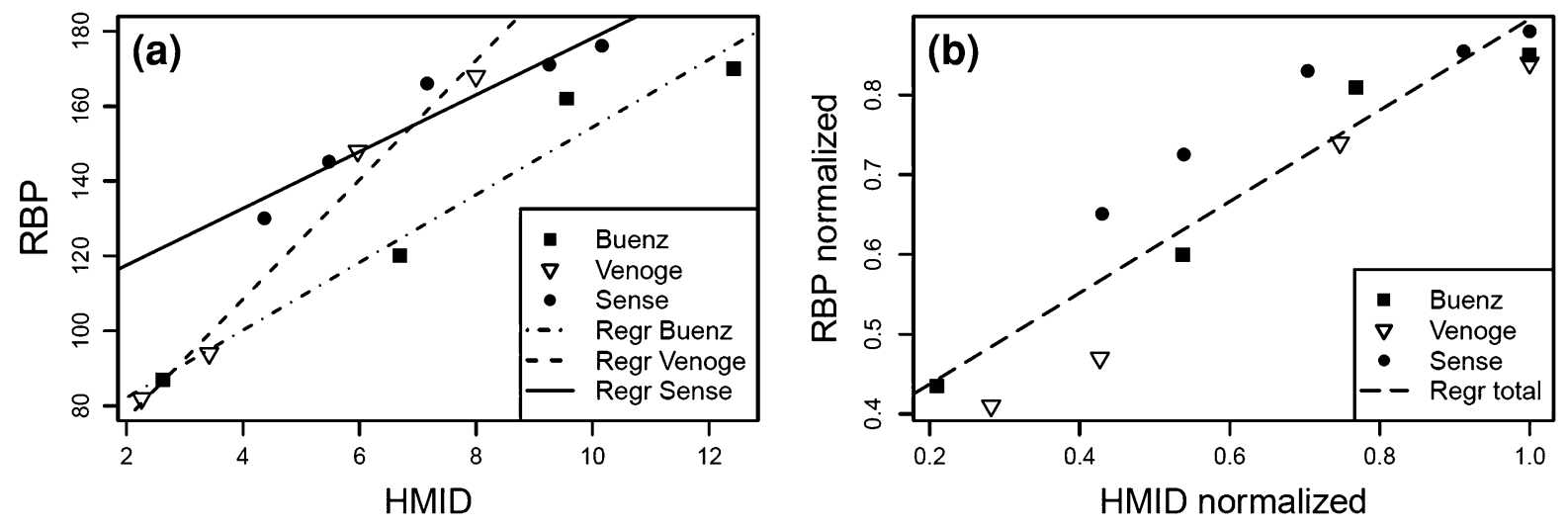

Fig. 6 Relation of the HMID to visual habitat assessment metric (RBP)

Application of HMID

By comparing the HMID with a visual assessment metric (RBP), we showed that the proposed HMID is able to reliably classify hydromorphological heterogeneity of a stream reach. Despite fundamentally different approaches behind the two measures, the correlation with RBP was strong. This correlation with a widely applied metric supports the validity of HMID, but does not mean that the two indices can substitute each other as HMID and RBP were developed for different applications and differ in some important characteristics. In contrast to the HMID, which is based on predictable statistical parameters of hydraulic variables, the RBP, acquired with visual assessment methods, while being appropriate as a method for evaluation of the present stream condition, cannot be used as a predictive tool.

The possibility of being used as a predictive tool to evaluate geomorphic measures in river engineering projects from an ecomorphological perspective is the key added value of HMID. Our index is particularly suitable for an application within the framework of river basin management plans that aim at both sustainable flood protection and enhancement of ecological status. In such projects, two-dimensional (2D) numerical models have become a standard for engineers to evaluate flood protection works (see e.g., River2D, Steffler \& Blackburn, 2002; Basement, Faeh et al., 2006-2011). If elaborated in a thorough manner, numerical models are able to represent the physical reality in a more reliable way than field measurements. Field measurements correspond to a single snapshot in time and are traditionally characterized by the onedimensionality of measurements because they are carried out along transects and are affected by operator variability (Wallis et al., 2010).

Numerical 2D models do not view the stream as a number of transects, but rather as a continuum (Ghanem et al., 1996) represented by a digital terrain model that is defined upon a topographic field survey containing information about altitude and roughness. In projects where a $2 \mathrm{D}$ model has been implemented, a very small surplus of time is needed to calculate the HMID for different project alternatives in order to determine the design alternative preferable from an ecomorphological point of view. The procedure to determine the HMID based on numerical modeling would start with running a steady $2 \mathrm{D}$ simulation with the topography of the project alternatives and the mean flow as input. Mean flow is usually defined based upon a flow duration curve specific for the study site. From the model output, the values of flow velocities and water depth for each grid cell of the modeling domain would be read out, then the statistical parameters $\mu$ and $\sigma$ for the pooled dataset would be computed, and finally the HMID for the site calculated. For an engineer with expertise in application of 2D models, the time needed to determine the HMID for a project alternative would be no more than a few hours.

\section{Constraints and caveats}

The HMID was developed to characterize river segments at the reach scale-the scale at which river rehabilitation measures are typically designed and 
implemented (Brierley \& Fryirs, 2005). We expect it to be of great assistance for the design of rehabilitation projects as it offers a quantitative evaluation tool of different project alternatives and can thus complement the guiding image concept which usually has its focus on qualitative statements. However, what happens at the reach scale is also influenced by larger scale processes (Thoms, 2006). For designing ecologically successful restoration projects, the use of reach scale tools like HMID that provide high habitat heterogeneity does not substitute the consideration of processes at the catchment and ecoregion scales (Palmer et al., 2005; Brierley \& Fryirs, 2008; Fryirs \& Brierley, 2008).

In particular, to obtain a dynamic equilibrium (Elosegi et al., 2010) with a capacity of self-adjustment must be a priority in stream restoration. In streams with an occurrence of periodical disturbances, represented by channel avulsion processes with habitat turnover during bankfull flow, the chance of reestablishing and maintaining a healthy biotic river community is high (Arscott et al., 2002). Therefore, in addition to assessments and predictions at the reach scale, for which the HMID can be a valuable tool, it is essential to consider catchment processes with regard to hydrologic regime, sediment supply, and transport (Kondolf et al., 2001, 2007). For example, a lack of sediment input from upstream may lead to an incision of the streambed where after some time, habitat heterogeneity will be impoverished again. If, in contrast, sediment yield is excessive or contains a high percentage of fines, the risk that key habitats will be siltated is high. The highest capacity of selfadjustment and long-term stability of habitat heterogeneity is expected in streams with an equilibrated sediment load. In such cases, channel avulsion events merely modify the design geometry, while preserving the variability of hydraulic variables and thus habitat heterogeneity at similar pre- and post events.

Furthermore, it should be kept in mind that physical heterogeneity alone, even in streams characterized by a dynamic equilibrium, does not make a healthy river. Numerous studies in the last decade (Larson et al., 2001; Negishi \& Richardson, 2003; Moerke et al., 2004; Lepori et al., 2005; Jähnig et al., 2009, 2010; Palmer et al., 2010) demonstrated that only restoring physical heterogeneity might be insufficient for recovering biotic quality. Reported failures could be attributed to other factors (such as chemical pollution or lack of catchment-scale connectivity), thereby overriding the effects of hydromorphological diversity. As a consequence, when habitat enhancement is a goal of restoration projects, the presence and extent of other potential stressors must also be ascertained from the beginning to prevent the project failure from an ecological point of view.

\section{Generality of HMID and outlook}

The HMID was developed for pre-alpine gravel-bed streams characterized by a large grain size and relatively steep slopes. However, improvement of spatial variability to offer a variety of habitats is a common principle in river rehabilitation that is valid for different river types. Thus, we expect that the HMID could also be applied for a much wider range of cases, although thresholds as described in the results between different classes might be different for other river types.

The described development of the HMID was based on spatial diversity measures obtained from field surveys at mean flow that represent a single snapshot in the year. The interaction between spatial variability and temporal dynamism is crucial for aquatic ecosystems; therefore, it is important to investigate conditions not only at mean flow stages, but also at low flows or higher flows with a reduced exceedence probability. In principle, it can be assumed that habitat diversity is less sensitive to flow changes in natural than in channelized reaches. As long as bottleneck conditions are absent, natural reaches usually maintain a greater habitat diversity even at low flow conditions. A further study is being carried out presently to enlighten this topic, thereby giving the index further descriptive and predictive power. Moreover, future activities will include the elaboration of application guidelines for the HMID in order to move from the research arena into practical application (see Dunbar et al., 2010). Altogether, we think that the HMID can become a valuable tool for predicting the change in local hydromorphology for different engineering scenarios. It will, however, need to be integrated with predictions for other catchment-scale morphological and biotic processes when the goal is improving the biotic quality.

Acknowledgments We thank Simone Blaser and Christa Jolidon for help in the field, Laura Vigne for hydromorphological data on the River Venoge, Pascale Derleth-Sartori 
(Canton Vaud) for valuable hints regarding the river Venoge, the team of Patscheider \& Partner Engineers (Italy) for great assistance in field work and elaboration of graphs, and the anonymous reviewers for helpful comments on the different stages of the manuscript. This project was funded by the Federal Department of the Environment (FOEN) and the Autonomous Province of South Tyrol/Italy.

\section{References}

Agences de l'Eau \& Ministère de l'Environnement, 1998. SEQ Physique: A System for the Evaluation of the Physical Quality of Watercourses.

Allan, J. D. \& M. M. Castillo, 2007. Stream Ecology. Structure and Function of Running Waters, 2nd ed. Springer, Dordrecht, Netherlands.

Armanini, D. G., N. Horrigan, W. A. Monk, D. L. Peters \& D. J. Baird, 2010. Development of a benthic macroinvertebrate flow sensitivity index for canadian rivers. River Research and Applications. doi:10.1002/rra.1389.

Armstrong, J. D., P. S. Kemp, G. J. A. Kennedy, M. Ladle \& N. J. Milner, 2003. Habitat requirements of Atlantic salmon and brown trout in rivers and streams. Fisheries Research 62: 143-170.

Arscott, D. B., K. Tockner, D. Nat \& J. V. van der Ward, 2002. Aquatic habitat dynamics along a braided Alpine river ecosystem (Tagliamento River, Northeast Italy). Ecosystems 5: 802-814.

Barbour, M. T. \& J. B. Stribling, 1991. Use of habitat assessment in evaluating the biological integrity of stream communities. In Biological Criteria: Research and Regulation: 25-38.

Barbour, M. T., J. Gerritsen, B. D. Snyder \& J. B. Stribling, 1999. Rapid Bioassessment Protocols for Use in Streams and Wadeable Rivers: Periphyton, Benthic Macroinvertebrates and Fish, Second Edition. EPA 841-B-99-002. U.S. Environmental Protection Agency, Office of Water, Washington, DC.

Bartley, R. \& I. Rutherford, 2005. Measuring the reach-scale geomorphic diversity of streams: application to a stream disturbed by a sediment slug. River Research and Applications 21: 39-59.

Bates, D. J., 2000. Comparison of select life history features in wild versus hatchery coastal cutthroat trout (Oncorhynchus clarki clarki) and the implications toward species fitness. $\mathrm{PhD}$ Dissertation, Department of Biological Sciences, Simon Fraser University, Burnaby, BC, Canada.

Beck, M. W., 1998. Comparison of the measurement and effects of habitat structure on gastropods in rocky intertidal and mangrove habitats. Marine Ecology Progress Series 169: $165-178$.

Bisson, P. A., K. Sullivan \& J. L. Neilson, 1998. Channel hydraulics, habitat use and body form of juvenile coho salmon, steelhead and cutthroat trout in streams. Transactions of the American Fisheries Society 117: 262-273.

Boavida, I., J. M. Santos, R. Cortes, A. Pinheiro \& M. T. Ferreira, 2011. Benchmarking river habitat improvement. River Research and Applications. doi:10.1002/rra. 1561.
Bovee, K. D., B. L. Lamb, J. M. Bartholow, C. B. Stalnaker, J. Taylor \& J. Henriksen, 1998. Stream Habitat Analysis Using the Instream Flow Incremental Methodology. Report USGS/ BRD-(1998)-004. U.S. Geological Survey, Biological Resources Division Information and Technology.

Brierley, G. J. \& K. A. Fryirs, 2005. Geomorphology and River Management: Application of the River Styles Framework. Blackwell, Oxford, UK.

Brierley, G. J. \& K. A. Fryirs, 2008. Space, place and a healthy dose of realism: grounding the process of river repair. In Gumiero, M. R. \& B. Fokkens (eds), 4th ECRR Conference on River Restoration, Italy, Venice S. Servolo Island. CIRF - Centro Italiano per la Riqualificazione Fluviale: 381-390.

Buffagni, A., S. Erba \& D. G. Armanini, 2009. The lentic-lotic character of Mediterranean rivers and its importance to aquatic invertebrate communities. Aquatic Sciences. doi:10.1007/s00027-009-0112-4.

Bunte, K. \& S. R. Abt, 2001. Sampling Surface and Subsurface Particle-Size Distributions in Wadable Gravel and CobbleBed Streams for Analysis in Sediment Transport, Hydraulics, and Streambed Monitoring. Gen. Tech. Rep. RMRS-GTR-74. U.S. Department of Agriculture, Forest Service, Rocky Mountains Research Station, Fort Collins, CO.

BUWAL, 1998. Methoden zur Untersuchung und Beurteilung der Fließgewässer: Modul-Stufen-Konzept. BUWAL-Reihe: Vollzug Umwelt. Bern, Bundesamt für Umwelt, Wald und Landschaft.

Conallin, J., E. Boegh \& J. K. Jensen, 2010. Instream physical habitat modelling types: an analysis as stream hydromorphological modelling tools for EU water resource managers. International Journal of River Basin Management 8: 93-107.

Dunbar, M. J., M. Warren, C. Extence, L. Baker, D. Cadman, D. J. Mould, J. Hall \& R. Chadd, 2010. Interaction between macroinvertebrates, discharge and physical habitat in upland rivers. Aquatic Conservation: Marine And Freshwater Ecosystems. doi:10.1002/aqc. 1089.

Elosegi, A., J. Diez \& M. Mutz, 2010. Effects of hydromorphological integrity on biodiversity and functioning of river ecosystems. Hydrobiologia 657: 199-215.

Emery, J. C., A. M. Gurnell, N. J. Clifford, G. E. Petts, I. P. Morrissey \& P. J. Soar, 2003. Classifying the hydraulic performance of riffle-pool bedforms for habitat assessment and river rehabilitation design. River Research and Applications 19: 533-549.

European Commission, 2000. Directive 2000/60/EC of the European Parliament and of the Council 23 October 2000: establishing a framework for community action in the field of water policy. Official Journal of the European Communities L327.

European Commission, 2007. Directive 2007/60/EC of the European Parliament and of the Council 23 October 2007 on the assessment and management of flood risks. Official Journal of the European Communities L288/27.

Extence, C. A., D. M. Balbi \& R. P. Chadd, 1999. River flow indexing using British benthic macroinvertebrates: a framework for setting hydroecological objectives. Regulated Rivers: Research \& Management 15: 543-574. 
Faeh, R., R. Mueller, P. Rousselot, D. Vetsch, C. Volz, L. Vonwiller, R. Veprek \& D. Farshi, 2006-2011. BASEMENT - Basic simulation environment for environmental flow and natural hazard simulation. Version 2.2. VAW, ETH Zurich.

Fleischhacker, T. \& K. Kern, 2002. Ecomorphological Survey of Large Rivers. German Federal Institute of Hydrology, Koblenz.

Fryirs, K. \& G. J. Brierley, 2008. The importance of reach sensitivity and catchment connectivity in river rehabilitation planning. In Gumiero, M. R. \& B. Fokkens (eds), IVth ECRR International Conference on River Restoration, Italy, Venice, San Servolo Island. CIRF - Centro Italiano per la Riqualificazione Fluviale: 401-408.

Ghanem, A., P. Steffler, F. Hicks \& C. Katopodis, 1996. Twodimensional hydraulic simulation of physical habitat conditions in flowing streams. Regulated Rivers: Research \& Management 12: 185-200.

Gibbins, C. N. \& R. M. Acornley, 2000. Salmonid habitat modelling studies and their contribution to the development of an ecologically acceptable release policy for Kielder Reservoir, North-East England. Regulated Rivers: Research \& Management 16: 203-224.

Gostner, W., A. J. Schleiss, W. K. Annable \& M. Paternolli, 2010. Gravel bar inundation frequency: an indicator for the ecological potential of a river. In Dittrich, A., J. Aberle \& P. Geisenhainer (eds), Proceedings of "River Flow 2010" Conference. Bundesanstalt für Wasserbau ISBN 978-3939230-00-7, Braunschweig: 1485-1493.

Graham, M. H., 2003. Confronting multicollinearity in ecological multiple regression. Ecology 84: 2809-2815.

Gurnell, A. M., G. E. Petts, D. M. Hannah, B. P. G. Smith, P. J. Edwards, J. Kollmann, J. V. Ward \& K. Tockner, 2001. Riparian vegetation and island formation along the gravelbed Fiume Tagliamento, Italy. Earth Surface Processes and Landforms 26: 31-62.

Heede, B. H. \& J. N. Rinne, 1991. Hydrodynamic in fluvial morphologic processes: implications for fisheries management and research. North American Journal of Fisheries Management 9: 35-43.

Jähnig, S. C., A. W. Lorenz \& D. Hering, 2008. Morphological parameters indicating differences between single- and multiple-channel mountain rivers in Germany, in relation to their modification and recovery. Aquatic Conservation: Marine and Freshwater Ecosystems 18: 1200-1216.

Jähnig, S. C., S. Brunzel, S. Gacek, A. W. Lorenz \& D. Hering, 2009. Effects of re-braiding measures on hydromorphology, floodplain vegetation, ground beetles and benthic invertebrates in mountain rivers. Journal of Applied Ecology 46: 406-416.

Jähnig, S. C., K. Brabec, A. Buffagni, S. Erba, A. W. Lorenz, T. Ofenböck, P. F. M. Verdonschot \& D. Hering, 2010. A comparative analysis of restoration measures and their effects on hydromorphology and benthic invertebrates in 26 central and southern European rivers. Journal of Applied Ecology 47: 671-680.

Jorde, K., M. Schneider \& F. Zöllner, 2000. Analysis of instream habitat quality - preference functions and fuzzy models. In Hu, W. (ed.), Stochastic Hydraulics 2000. Balkema, Rotterdam: 671-680.
Jowett, I. G., 1997. Instream flow methods: a comparison of approaches. Regulated Rivers: Research and Management 13: 115-127.

Jungwirth, M., S. Muhar \& S. Schmutz, 2002. Re-establishing and assessing ecological integrity in riverine landscapes. Freshwater Biology 47: 867-887.

Jungwirth, M., G. Haidvogl, O. Moog, S. Muhar \& S. Schmutz, 2003. Angewandte Fischökologie an Fließgewässern. Facultas Universitätsverlag, Wien.

Kern, K., 1992. Restoration of lowland rivers: the German experience. In Carling, P. A. \& G. E. Petts (eds), Lowland Floodplain Rivers: Geomorphological Perspectives. John Wiley \& Sons Ltd., Chichester, UK: 279-297.

Kondolf, G. M., M. W. Smeltzer \& S. Railsbach, 2001. Design and performance of a channel reconstruction project in a coastal California gravel-bed stream. Environmental Management 28: 761-776.

Kondolf, G. M., S. Anderson, R. Lave, L. Pagano, A. Merenlender \& E. S. Bernhardt, 2007. Two decades of river restoration in California: what can we learn? Restoration Ecology 15: 516-523.

Lamouroux, N. \& I. G. Jowett, 2005. Generalized instream habitat models. Canadian Journal of Fisheries and Aquatic Sciences 62: 7-14.

Lamouroux, N., H. Capra \& M. Pouilly, 1998. Predicting habitat suitability for lotic fish: linking statistical hydraulic models with multivariate habitat use models. Regulated Rivers: Research and Management 14: 1-11.

Larson, M. G., D. B. Booth \& S. A. Morley, 2001. Effectiveness of large woody debris in stream rehabilitation projects in urban basins. Ecological Engineering 18: 211-226.

LAWA, 1999. Gewässerstrukturgütekartierung in der Bundesrepublik Deutschland. Übersichtsverfahren. Länderarbeitsgemeinschaft Wasser, Munich.

LAWA, 2000a. Gewässerstrukturgütekartierung in der Bundesrepublik Deutschland. Handbuch zum Übersichtsverfahren. Länderarbeitsgemeinschaft Wasser, Munich.

LAWA, 2000b. Gewässerstrukturgütekartierung in der Bundesrepublik Deutschland. Verfahrensbeschreibung für Vor-Ort-Kartierungen kleiner bis mittelgroßer Fließgewässer. Länderarbeitsgemeinschaft Wasser, Munich.

Lepori, F., D. Palm, E. Brännäs \& B. Malmqvist, 2005. Does restoration of structural heterogeneity in streams enhance fish and macroinvertebrate diversity? Ecological Applications 15: 2060-2071.

Maddock, I., 1999. The importance of physical habitat assessment for evaluating river health. Freshwater Biology 41: 373-391.

Malmqvist, B. \& S. Rundle, 2002. Threats to the running water ecosystems of the world. Environmental Conservation 29: 134-153.

McCormick, M. I., 1994. Comparison of field methods for measuring surface topography and their associations with a tropical reef assemblage. Marine Ecology Progress Series 112: 87-96.

Miller, S. W., P. Budy \& J. C. Schmidt, 2009. Quantifying macroinvertebrate responses to in-stream habitat restoration: applications of meta-analysis to river restoration. Restoration Ecology 18: 8-19. 
Minshall, G. W., 1984. Aquatic insect substratum relationships. In Resh, V. H. \& D. M. Rosenberg (eds), Ecology of Aquatic Insects. Praeger Publishers, New York: 359-400.

Moerke, A. H., K. J. Gerard, J. A. Latimore, R. A. Hellenthal \& G. A. Lamberti, 2004. Restoration of an Indiana, USA, stream: bridging the gap between basic and applied lotic ecology. Journal of the North American Benthological Society 23: 647-660.

Monk, W. A., P. J. Wood, D. M. Hannah \& D. A. Wilson, 2008. Macroinvertebrate community response to inter-annual and regional river flow regime dynamics. River Research and Applications 24: 988-1001.

Muhar, S., M. Schwarz, S. Schmutz \& M. Jungwirth, 2000. Identification of rivers with high and good habitat quality: methodological approach and applications in Austria. Hydrobiologia 422(423): 343-358.

Negishi, J. N. \& J. S. Richardson, 2003. Responses of organic matter and macroinvertebrates to placements of boulder clusters in a small stream of southwestern British Columbia, Canada. Canadian Journal of Fisheries and Aquatic Sciences 60: 247-258.

Palmer, M. A., C. C. Hakenkamp \& K. Nelson Baker, 1997. Ecological heterogeneity in streams: why variance matters. Journal of the North American Benthological Society 16: 189-202.

Palmer, M. A., E. S. Bernhardt, J. D. Allan, P. S. Lake, G. Alexander, S. Brooks, J. Carr, S. Clayton, C. N. Dahm, J. Follstad Shah, D. L. Galat, S. G. Loss, P. Goodwin, D. D. Hart, B. Hassett, R. Jenkinson, G. M. Kondolf, R. Lave, J. L. Meyer, T. K. O’Donnell, L. Pagano, P. Srivastava \& E. Sudduth, 2005. Standards for ecologically successful river restoration. Journal of Applied Ecology 42: 208-217.

Palmer, M. A., H. L. Menninger \& E. Bernhardt, 2010. River restoration, habitat heterogeneity and biodiversity: a failure of theory or practice? Freshwater Biology 55: 205-222.

Parasiewicz, P., 2001. MesoHABSIM: a concept for application of instream flow models in river restoration planning. Fisheries Research 26: 6-13.

Parsons, M., M. Thoms \& R. Norris, 2002a. Australian River Assessment System: AusRivAS Physical Assessment Protocol, Monitoring River Health Initiative. Technical Report no 22, Commonwealth of Australia and University of Canberra, Canberra.

Parsons, M., M. Thoms \& R. Norris, 2002b. Australian River Assessment System. Review of Physical River Assessment Methods: A Biological Perspective. Cooperative Research Centre for Freshwater Ecology, University of Canberra, Canberra.

Petersen Jr., R. C., 1992. The RCE: a riparian, channel and environmental inventory for small streams in the agricultural landscape. Freshwater Biology 27: 295-306.

Plafkin, J. L., M. T. Barbour, K. D. Porter, S. K. Gross \& R. M. Hughes, 1989. Rapid Bioassessment Protocols for Use in Streams and Rivers: Benthic Macroinvertebrates and Fish. EPA/444/4-89-001. U.S. Environmental Protection Agency, Office of Water, Washington.

R Development Core Team, 2010. R: A Language and Environment for Statistical Computing. R Foundation for Statistical Computing, Vienna, Austria. ISBN 3-900051-07-0, URL http://www.R-project.org.
Rankin, E. T., 1995. The use of habitat assessments in water resource management programs. In Simon, W. D. T. (ed.), Biological Assessment and Criteria: Tools for Water Resource Planning and Decision Making. Lewis Publishers, Boca Raton, FL: 181-208.

Raven, P. J., N. T. H. Holmes, M. Naura \& F. H. Dawson, 2000. Using river habitat survey for environmental assessment and catchment planning in the U.K. Hydrobiologia 422(423): 359-367.

Rossi, R. E., D. J. Mulla, A. G. Journel \& E. H. Franz, 1992. Geostatistical tools for modeling and interpreting ecological spatial dependence. Ecological Monographs 62: 277-314.

Schleiss, A. J., 2005. Flussbauliche Hochwasserschutzmaßnahmen und Verbesserung der Gewässerökologie - Vorschlag eines hydraulisch - morphologischen Vielfältigkeitsindexes. Wasser, Energie, Luft 97: 195-199.

Schmedtje, U., 1996. Ökologisch begründete Festlegung von Mindestabflüssen: die zentrale Bedeutung der sohlennahen Strömungsverhältnisse. Wasserwirtschaft 86: 326-330.

Schneider, D. C., 1994. Quantitative Ecology: Spatial and Temporal Ecology. Academic Press, San Diego.

Siligardi, M., S. Bernabei, C. Cappelletti, E. Chierici, F. Ciutti, F. Egaddi, F. Franceschini, B. Maiolini, L. Mancini, M.R. Minciardi, C. Monauni, G. Rossi, G. Sansoni, R. Spaggiari \& M. Zanetti, 2000. I. F. F. Indice di Funzionalità Fluviale. Manuale NPA.

Simonson, D. S., J. Lyons \& P. D. Kanehl, 1994. Quantifying fish habitat in streams: transect spacing, sample size, and a proposed framework. North American Journal of Fisheries Management 14: 607-615.

Statzner, B., J. A. Gore \& V. H. Resh, 1988. Hydraulic stream ecology: observed patterns and potential applications. Journal of the North American Benthological Society 7: 307-360.

Statzner, B., F. Kohmann \& A. G. Hildrew, 1991. Calibration of FST-hemispheres against bottom shear stress in a laboratory flume. Freshwater Biology 26: 227-231.

Steffler, P. M. \& J. Blackburn, 2002. River2D: Two-Dimensional Depth-Averaged Model of River Hydrodynamics and Fish Habitats. University of Alberta, Edmonton, Canada.

Thoms, M. C., 2006. Variability in riverine ecosystems. River Research and Applications 22: 115-121.

Thorp, J. H., M. C. Thoms \& M. D. Delong, 2006. The riverine ecosystem synthesis: biocomplexity in river networks across space and time. River Research and Applications 22: 123-147.

Thorp, J. H., J. E. Flotemersch, M. D. Delong, A. F. Casper, M. C. Thoms, F. Ballantyne, B. S. Williams, B. J. O’Neill \& C. S. Haase, 2010. Linking ecosystem services, rehabilitation, and river hydrogeomorphology. BioScience 60: 67-74.

Vaughan, I. P., M. Diamond, A. M. Gurnell, K. A. Hall, A. Jenkins, N. J. Milner, L. A. Naylor, D. A. Sear, G. Woodward \& S. J. Ormerod, 2009. Integrating ecology with hydromorphology: a priority for river science and management. Aquatic Conservation: Marine and Freshwater Ecosystems 19: 113-125.

Vörösmarty, C. J., P. B. McIntyre, M. O. Gessner, D. Dudgeon, A. Prusevich, P. Green, S. E. Bunn, C. A. Sullivan, C. Reidy Liermann \& P. M. Davies, 2010. Global threats to 
human water security and river biodiversity. Nature 467: $555-561$.

Wallis, C., I. Maddock, F. Visser \& M. Acreman, 2010. A framework for evaluating the spatial configuration and temporal dynamics of hydraulic patches. River Research and Applications. doi:10.1002/rra.1468.

Wolman, M. G., 1954. A method of sampling coarse bed material. American Geophysical Union, Transactions 35: 951-956.
Woolsey, S., F. Capelli, T. Gonser, E. Hoehn, M. Hostmann, B. Junker, A. Paetzold, C. Roulier, S. Schweizer, S. D. Tiegs, K. Tockner, C. Weber \& A. Peter, 2007. A strategy to assess river restoration success. Freshwater Biology 52: 752-769.

Zappia, H. \& D. C. Hayes, 1998. A Demonstration of the Instream Flow Incremental Methodology, Shenandoah River, Virginia Report: 98-157. U.S. Geological Survey, Water Resources Investigations. 